\title{
Investigation of Ultra High Strength Steel with 3DTEM and 3D Atom Probe
}

\author{
M. Hartshorne*, C. McCormick*, P. Novotny**, M. Schmidt***, D.N. Seidman**** and M.L. \\ Taheri \\ *Department of Materials Science, Lebow 344, Drexel University, Philadelphia, PA 19104 \\ ** Tool and Alloy R\&D, Carpenter Technology Corporation, Reading, PA 19601 \\ *** Stainless Steel Alloy R\&D, Carpenter Technology Corporation, Reading, PA 19601 \\ $* * * *$ Northwestern Center for Atom Probe Tomography, Northwestern University, Evanston, IL \\ 60208
}

Ultra High Strength (UHS) Steels are used in critical applications such as landing gear, structural members, springs and engine components. The performance of these alloys in aviation is especially important due to the finer tolerances and lower safety factors of these components. These steels traditionally have necessitated high levels of alloying elements and extremely low levels of impurities to achieve the required level of fracture toughness for advanced applications. Novotny et al. at Carpenter Technology Corporation have developed a new family of martensitic UHS steels which utilize much lower levels of a more complex array of alloying elements than have been previously employed. (Figures 1 and 2) This alloy system possesses comparable strength and fracture toughness to much more highly alloyed steels, while at the same time offering decreased costs [1]. The strengthening mechanisms operating in this new alloy system are not well understood, and an analysis of the segregation of the solute elements and structure of any precipitates formed is desired to further improve this alloy. The behavior of precipitates and solute elements in these steels can be more thoroughly studied by utilizing a combination of TEM and 3D Atom Probe tomography.

We will present experiments detailing the crystallographic relationship of precipitates to the surrounding matrix and other nearby microstructural features such as grain and lath boundaries as determined by utilizing a combination of three-dimensional transmission electron microscopy (3DTEM) and selected area electron diffraction (SAD). We will correlate the structure and the chemistry of the precipitates using energy dispersive x-ray spectroscopy (EDS) and SAD. Site specific samples containing prior austenite grain boundaries will be prepared for threedimensional atom probe tomography (3DAP) and analyzed using 3DTEM before destructive analysis using 3DAP.[2] This will allow the high chemical and depth resolution of 3DAP [3,4] to be correlated to the 3D model generated using the tilt series captured in 3DTEM at the same, site specific location to study the grain boundaries, solute segregation and the finest of precipitates.[5,6] The combination of these techniques will allow closer correlated to the high resolution TEM (HRTEM) images of the grain boundaries in question.

The combination of atomic level resolution microscopy and tomographic techniques allow an indepth analysis of the microstructure of this new alloy system, and permit us to elucidate the microstructural mechanisms which give rise to the high strength and high fracture toughness.[7]

References

[1] Carpenter Technology, 2009.

[2] M.L. Taheri, et al. Ultramicrosc. Article in Press, available online 23 Dec. 2009. 
[3] M.K. Miller and R.G. Forbes. Mater. Charact. 60 (2009) 461.

[4] Baptiste Gault, et al. Microsc. Microanal.16 (2010) 99.

[5] A. J. Koster, et al. J. Phys. Chem. 104 (2000) 9368.

[6] I.K. Arson, et al. Ultramiscrosc. 108 (2008) 1589

[7] This work is supported by Carpenter Technology Corporation and Drexel University. This research was made possible by use of the Centralized Research Facilities in the College of Engineering at Drexel University.

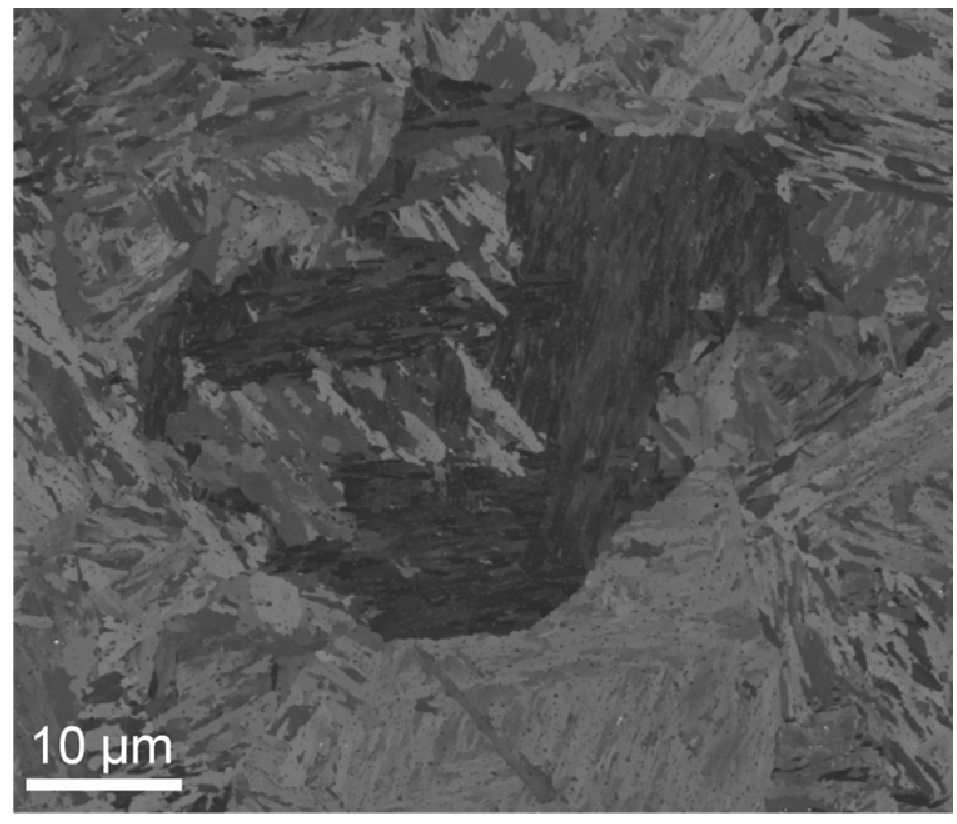

FIG 1: $30 \mathrm{kV}$ Gallium ion image of UTS steel. Image shows martensitic lath structure.

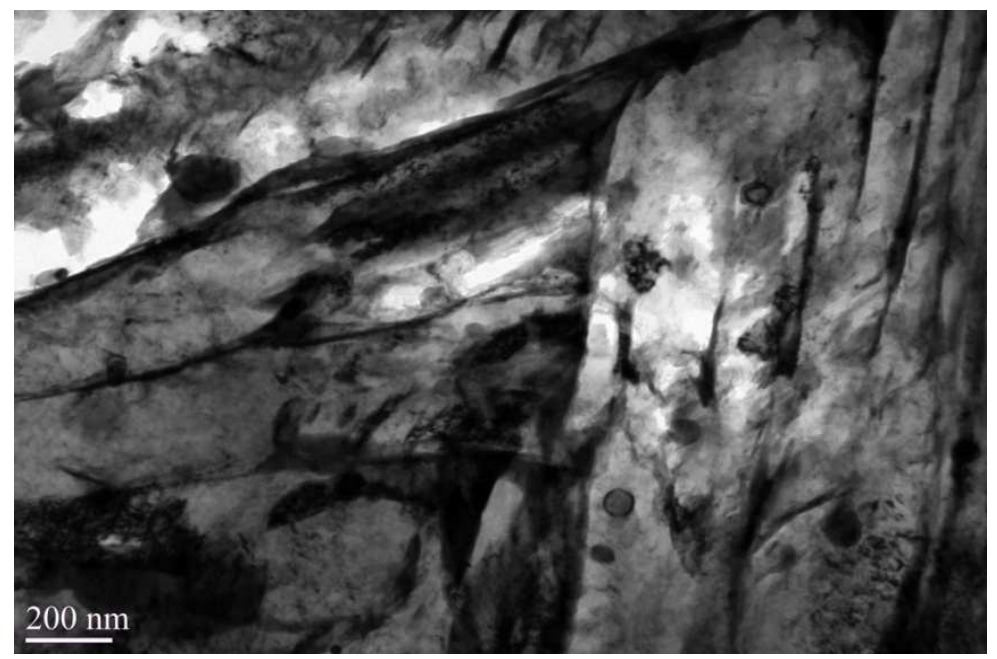

FIG 2: $200 \mathrm{kV}$ TEM bright field image. Image shows precipitates within martensitic laths. 